\title{
Correction to: The pragmatic, rapid, and iterative dissemination and implementation (PRIDI) cycle: adapting to the dynamic nature of public health emergencies (and beyond)
}

\author{
Reza Yousefi Nooraie ${ }^{1,2^{*}} \mathbb{C}$, Rachel C. Shelton ${ }^{3}$, Kevin Fiscella ${ }^{4}$, Bethany M. Kwan ${ }^{5}$ and James M. McMahon ${ }^{6}$
}

\section{Correction to: Health Res Policy Sys (2021) 19:110} https://doi.org/10.1186/s12961-021-00764-4

Following the publication of the original article [1], we were notified that an out-of-place circle had been mistakenly included in Fig. 1, without any impact on the scientific content of the figure.

The original article has now been corrected.

\section{Author details}

'Department of Public Health Sciences, University of Rochester, Rochester, NY, USA. ${ }^{2}$ Institute of Health Policy, Management, and Evaluation, University of Toronto, Toronto, Canada. ${ }^{3}$ Department of Sociomedical Sciences, Columbia University, New York, NY, USA. ${ }^{4}$ Department of Family Medicine, University of Rochester, Rochester, NY, USA. ${ }^{5}$ Department of Family Medicine, University of Colorado Anschutz Medical Campus, Aurora, CO, USA. ${ }^{6}$ School of Nursing, University of Rochester, Rochester, NY, USA.

Published online: 19 August 2021

\section{Reference}

1. Yousefi Nooraie R, Shelton RC, Fiscella K, Kwan BM, McMahon JM. The pragmatic, rapid, and iterative dissemination and implementation (PRIDI) cycle: adapting to the dynamic nature of public health emergencies (and beyond). Health Res Policy Sys. 2021;19:110. https://doi.org/10.1186/ s12961-021-00764-4.

\section{Publisher's Note}

Springer Nature remains neutral with regard to jurisdictional claims in published maps and institutional affiliations. to the material. If material is not included in the article's Creative Commons licence and your intended use is not permitted by statutory regulation or exceeds the permitted use, you will need to obtain permission directly from the copyright holder. To view a copy of this licence, visit http://creativecommons.org/licenses/by/4.0/. The Creative Commons Public Domain Dedication waiver (http://creativecommons.org/publicdomain/zero/1.0/) applies to the data made available in this article, unless otherwise stated in a credit line to the data. 